\title{
Utilização da levedura desidratada (Saccharomyces cerevisiae) para leitões na fase inicial
}

\author{
Dried yeast (Saccharomyces cerevisiae) utilization for piglets in the initial phase
}

\author{
Lúcio Francelino Araújo ${ }^{1}$ Otto Mack Junqueira ${ }^{2}$ Eurípedes Laurindo Lopes ${ }^{3}$ \\ Cristiane Soares da Silva Araújo ${ }^{2}$ Josiane Hernandes Ortolan ${ }^{4}$ \\ Antônio Carlos de Laurentiz ${ }^{2}$
}

\section{RESUMO}

Foi conduzido um experimento com o objetivo de avaliar o efeito da adição de diferentes níveis de levedura (Saccharomyces cerevisiae) desidratada na ração sobre o desempenho e a morfologia intestinal de leitões na fase inicial. Foram utilizados 280 leitões (fêmeas e machos castrados) de uma linha genética comercial de suínos, desmamados com 21 dias de idade e distribuídos em 20 baias, de acordo com o delineamento em blocos ao acaso, com 5 repetições e 4 tratamentos experimentais (0, 5, 10 e 15\% de adição de levedura). Aos 45 dias de idade, três leitões de cada tratamento foram abatidos e colhidas amostras do duodeno e do jejuno para estudo da morfologia intestinal. Os níveis crescentes de levedura desidratada nas rações não afetaram $(P>0,05)$ o ganho de peso, o consumo de ração e a conversão alimentar dos leitões. Com relação à morfologia do duodeno e do jejuno, também não houve efeito $(P>0,05)$ dos níveis de levedura estudados sobre a altura das vilosidades, das profundidades das criptas e da relação vilosidade/cripta. Os resultados permitiram concluir que a levedura desidratada pode ser adicionada em até $15 \%$ nas rações de suínos na fase inicial.

Palavras-chave: leitões, levedura desidratada, morfologia intestinal, nutrição.

\section{ABSTRACT}

An experiment was conducted to evaluate the effect of different levels of dried yeast (Saccharomyces cerevisiae) in diets about performance and intestinal morphology of piglets at initial phase. They used 280 piglets (females and castrated males) from genetic lines, weaned with 21 days of age, allocated in 20 pens in randomized design blocks, with 5 replications and 4 treatments $(0,5,10$ and $15 \%$ dried yeast addition). Samples of duodenum and jejunum of 3 piglets slaughtered at 45 days of age were collected from each treatment to study intestinal morphology. The increasing levels of dried yeast in rations did not affect significantly the weight gain, feed intake and feed conversion. In relation of duodenum and jejunum there was no significative effect $(P>0.05)$ of dried yeast increased levels on villous height, crypt depth and villous crypt ratio. The results allowed to conclude that dried yeast can be added up to $15 \%$ in initial phase piglets diets.

Key words: dried yeast, morphology intestinal, nutrition, piglets.

\section{INTRODUÇÃo}

O aumento verificado no consumo de alimentos devido ao crescimento da população vem se constituindo em um grande estímulo à suinocultura nos últimos anos. Os freqüentes aumentos nos preços de cereais e de suplementos protéicos vegetais utilizados na alimentação dos animais domésticos têm despertado um grande interesse pelo aproveitamento de alimentos conhecidos como não convencionais.

Entre as fontes alternativas pesquisadas, grande atenção é dada aos microorganismos, entre os quais se destacam as leveduras, já que o Brasil é o maior produtor mundial de álcool de cana-de-açúcar,

\footnotetext{
${ }^{1}$ Departamento de Zootecnia da Faculdade de Zootecnia e Engenharia de Alimentos (FZEA), Universidade de São Paulo (USP), Av. Duque de Caxias Norte, 225, CP 23, 13635-900, Pirassununga, SP, Brasil. Email: lfaraujo@usp.br.

${ }^{2}$ Departamento de Zootecnia da Faculdade de Ciências Agrárias e Veterinárias (FCAV), Universidade Estadual Paulista (UNESP), 14870-000, Jaboticabal, SP, Brasil.

${ }^{3}$ Departamento de Zootecnia da Escola de Veterinária (EV), Universidade Federal de Goiás (UFG), 74000-000, Goiânia, GO, Brasil. ${ }^{4}$ Departamento de Zootecnia, FZEA-USP, Pirassununga, SP, Brasil.
} 
sendo que sua indústria alcooleira se acha em plena expansão (FARIA et al., 2000).

De acordo com MOREIRA et al. (2002), existem variadas formas para a obtenção da levedura seca, dentre as quais destacam-se a sangria do leite de levedura, do fundo de dorna e da vinhaça. Após a obtenção do produto úmido, existem ainda duas técnicas de secagem: por rolos rotativos e, mais recentemente, pela tecnologia “spray-dry”. O primeiro método é o mais utilizado e consiste na secagem do leite de levedura por meio do contato direto com a superfície aquecida do rolo rotativo, atingindo temperaturas de até $200^{\circ} \mathrm{C}$ (LANDELL FILHO et al.,1994). Já o segundo processo é constituído pelo bombeamento do leite de levedura em uma câmara de secagem, passando por um cabeçote atomizador que, girando a altíssima rotação, atomiza o leite em pequenas gotículas e, combinado com o fluxo de ar quente, secao instantaneamente. A levedura seca é recolhida no fundo da câmara, em forma de cone. O produto é descarregado através de uma válvula rotativa, onde está pronto para ser ensacado na forma de pó fino (MOREIRA et al., 1998).

De maneira geral, elas têm apresentado valores entre 27 e $31 \%$ de proteína bruta (ZANUTTO, 1997). São consideradas boas fontes de aminoácidos, principalmente lisina, o que as torna importantes na combinação com grãos de cereais, especialmente com o milho, que é deficiente neste aminoácido. Os carboidratos representam 45 a 55\% do peso da levedura, sendo representados em média por 33\% de trealose, $27 \%$ de glucanos, $21 \%$ de mananoligossacarídeos e $12 \%$ de glicogênio (BATTISTI et al., 1985). A fração do extrato etéreo é baixa e compreende aproximadamente proporções iguais de triglicerídeos e fosfolipídeos. Quanto à fração inorgânica, as leveduras possuem elevado conteúdo de matéria mineral, variando de 4 a $14 \%$, sendo ricas em potássio e fósforo, principalmente como conseqüência de tampões, sais e outros aditivos incorporados ao substrato para melhorar o rendimento e reduzir o tempo de fermentação (FIALHO et al., 1985). O enxofre aparece na forma de sulfitos. Os níveis de fibra bruta são normalmente inferiores a $1 \%$.

Avaliando o efeito de três níveis de levedura desidratada ( $0 \%, 15 \%$ e $30 \%)$ como fonte protéica para suínos na fase inicial, MIYADA et al. (1992) verificaram piora na conversão alimentar dos animais com o aumento dos níveis da levedura na ração e sugeriram que $10 \%$ é o nível mais adequado de inclusão.

Vários trabalhos têm procurado demonstrar o efeito de diferentes fontes protéicas sobre a morfologia intestinal de leitões desmamados. As condições das vilosidades e das criptas dependem, diretamente, do tipo de alimento ingerido e da fase em que o animal se encontra (CERA et al., 1988). A presença de duas proteínas encontradas na soja, glicina e ßconglicina, as quais têm ação antigênica sobre o lúmen intestinal, desencadeiam uma resposta imunológica atrofiando as vilosidades e aumentando a profundidade das criptas (FRIESEN et al., 1993).

O objetivo do presente trabalho foi avaliar o efeito da utilização na ração de diferentes níveis de levedura desidratada (Saccharomyces cerevisiae), obtida por spray-dry, sobre o desempenho e a morfologia intestinal de leitões na fase inicial.

\section{MATERIAL E MÉTODOS}

Foram utilizados 280 leitões (140 machos castrados e 140 fêmeas) de uma linhagem comercial de suínos em um período experimental de 49 dias, de seus 22 a 71 dias de idade, com peso inicial de 6,05 $\pm 0,26 \mathrm{~kg}$, distribuídos em delineamento de blocos casualizados com 4 tratamentos $(0,5,10$ e 15\% de inclusão da levedura seca) e 5 repetições de 14 animais cada.

O experimento foi conduzido em uma instalação de creche de uma granja comercial de suínos. Os animais foram alimentados com rações em duas fases distintas (I - 22 a 45 e II -46 a 71 dias de idade), nas quais a levedura foi adicionada nos níveis de $0,5,10$ e 15\%. A composição das rações experimentais se encontra na tabela 1 . Os animais receberam ração e água ad libitum. Após o término do período experimental, três animais de cada tratamento foram abatidos por meio da secção da veia jugular para coleta de fragmentos do intestino delgado.

Os parâmetros zootécnicos avaliados foram: ganho de peso (kg), consumo de ração (kg) e índice de conversão alimentar. Os animais foram pesados no início de cada período experimental, aos 45 dias (na mudança da ração) e ao término do experimento.

Quanto às características morfométricas dos cortes histológicos intestinais (duodeno e jejuno) avaliadas a altura das vilosidades (mm), a profundidade de cripta (mm) e a relação vilosidade:cripta, seguindose a metodologia descrita por LOPES et al. (2005).

Amostras de aproximadamente $2,5 \mathrm{~cm}$ de comprimento retirados da porção média dos segmentos do duodeno e do jejuno foram coletadas de cada animal, abertas pela borda mesentérica, lavadas em água destilada, estendidas pela túnica serosa e fixadas em solução de Bouin, em frascos de vidros identificados com o número de cada animal, para posterior processamento. Depois de 24 horas na solução fixadora de Bouin, as amostras foram lavadas em álcool etílico a 70\%, e posteriormente desidratadas em série crescente de álcoois. Após desidratação, foram recortadas, diafanizadas em benzol e incluídas 
Tabela 1 - Composição percentual das rações experimentais nas fases I e II

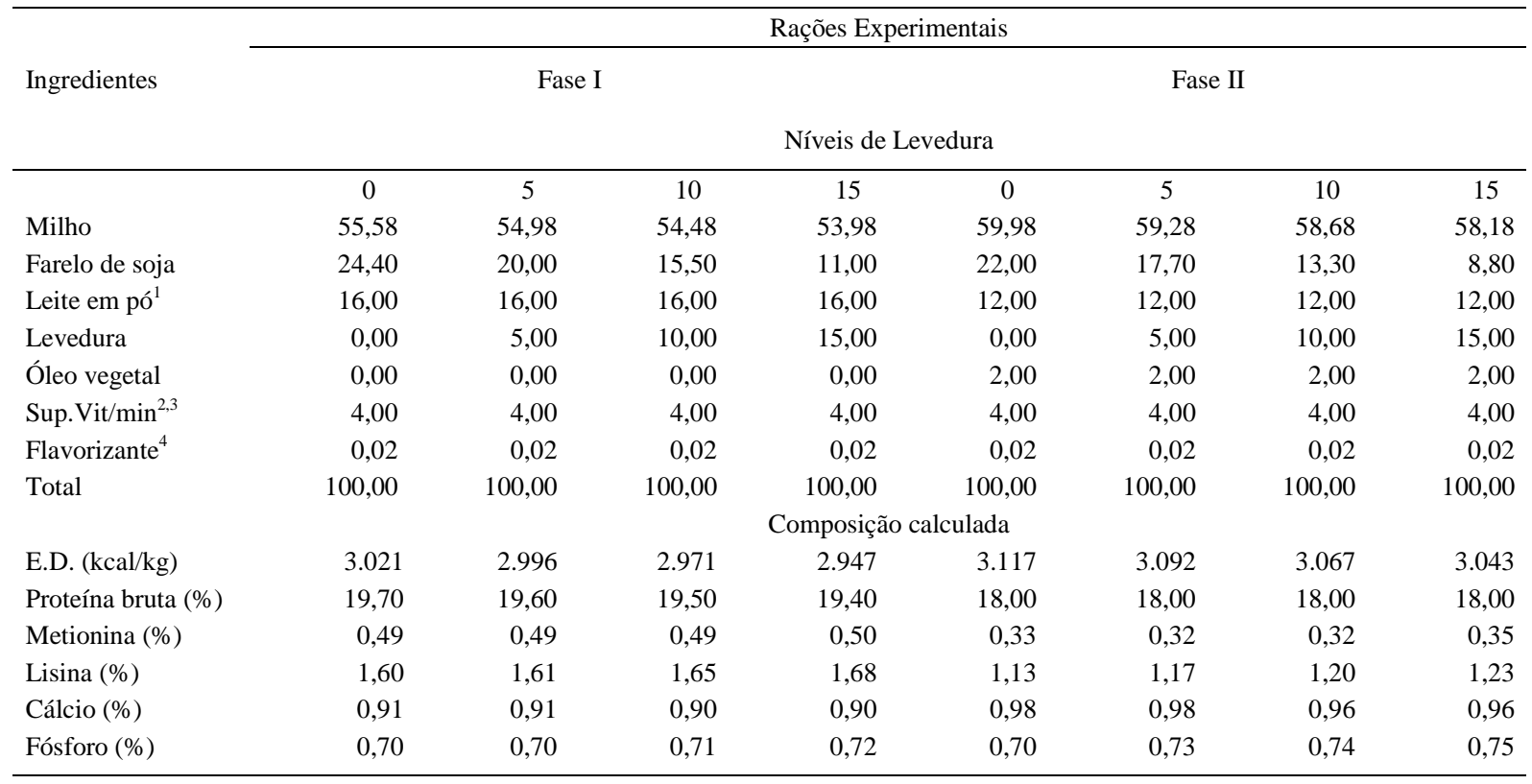

${ }^{1}$ Leite em pó - PB: 22\%; ED: 3.560kcal/kg-1 ; Lactose: 45\%; Ca: 0,9\%; Met: 0,33\%; Lis: 2,74\%.

${ }^{2}$ Composição/kg do produto -Fase I - Vit A: 300.000 UI; Vit $\mathrm{D}_{3}$ : 75.000 UI; Vit E: 1.324mg; Vit $\mathrm{B}_{1}$ : 36mg; Vit $\mathrm{B}_{2}$ : 220mg; Vit $\mathrm{B}_{12}$ : 0,94mg; Vit $K_{3}$ : 85mg; Ác. Pantotênico: 484mg; Biotina: 3,75mg; Niacina: 919mg; DL - Metionina: 45g; Colina: 14g; L-Lisina: 80g; Virginiamicina: 1g; Carbadox: 12,60g; I: 37,5g; Se: 5,5g; Cu: 3,15g; Mg: 1,5g; Zn: 2,6g; Fe: 1,9g; P: 62g; Ca: 160g; NaCl: 125g; BHT:3,2g; veículo (q.s.p.): $1.000 \mathrm{~g}$.

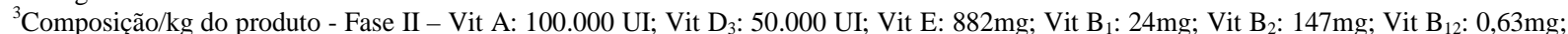
Vit $K_{3}$ : 56mg; Ác. Pantotênico: 323mg; Biotina: 2,50mg; Niacina: 612mg; DL - Metionina: 22g; Colina: 14g; L-Lisina: 124g; Nitrovin: 6g; Carbadox: 13g; I: 25g; Se: 3,7g; Cu: 3,13g; Mg: 1,5g; Zn: 2,6g; Fe: 1,9g; P: 65g; Ca: 199g; NaCl: 125g; BHT: 3g; veículo (q.s.p.): 1.000g.

${ }^{4}$ Aroma B.B.L. (Grisbill S.A.)

em parafina para se obter cortes longitudinais da mucosa intestinal.

Em cada lâmina histológica foram colocados 6 cortes semi-seriados com $5 \mathrm{~mm}$ de espessura, sendo que entre um corte e o subseqüente foram desprezados 6 cortes. Os cortes foram corados segundo as técnicas da hematoxilina de Harris-eosina. Com as lâminas prontas, foram efetuadas 30 medidas de altura de vilosidades (micra) e 30 de profundidade de cripta (micra) para o segmento do duodeno coletado.

As medidas de altura dos vilos foram tomadas a partir da região basal, que coincide com a porção superior das criptas, percorrendo-a longitudinalmente até seu ápice e suas criptas, da sua base até a região de transição cripta-vilo. A análise morfométrica do intestino delgado foi realizada em um sistema analisador de imagens da KONTRON ELEKTRONIK(Vídeo Plan), através de microscopia de luz, com aumento de 230 vezes.

As análises estatísticas foram realizadas utilizando-se o programa computacional SAS (2001) e as médias dos tratamentos, em caso de significância estatística, foram comparadas pelo teste de Tukey ao nível de 5\%. Foi efetuada análise de regressão polinomial, considerando como variável o nível de inclusão da levedura, sendo utilizado o seguinte modelo estatístico:

$\mathrm{Y}_{\mathrm{ij}}=\mathrm{m}+\mathrm{T}_{\mathrm{i}}+\mathrm{B}_{\mathrm{j}}+\mathrm{e}_{\mathrm{ij}}$, onde:

$\mathrm{Y}_{\mathrm{ij}}$ - valor observado na parcela com tratamento i e bloco j;

$\mathrm{m}$ - média geral;

$\mathrm{T}_{\mathrm{i}}$ - efeito dos níveis $\mathrm{i}$;

$\mathrm{B}_{\mathrm{j}}$ - efeito do bloco $\mathrm{j}$;

$\mathrm{e}_{\mathrm{ij}}$ - erro aleatório associado com cada observação $\mathrm{Y}_{\mathrm{ij}}$.

\section{RESULTADOS E DISCUSSÃO}

Os resultados de análise de variância do desempenho nas fases I (22 a 45) e II (46 a 71 dias) encontram-se na tabela 2 . No período de 22 a 45 dias, pode-se observar que não houve diferença $(\mathrm{P}>0,05)$ para ganho de peso, consumo de ração e conversão alimentar. Os animais que receberam a ração contendo 5\% de levedura desidratada apresentaram uma melhora, embora não significativa, no ganho de peso e na conversão alimentar em 5,43 e 7,77\%, respectivamente, com relação aos animais que receberam a ração basal, 
Tabela 2 - Ganho de peso diário (GMD), consumo médio diário (CMD) e conversão alimentar (CA) de leitões alimentados com rações contendo diferentes níveis de levedura desidratada nas Fases I e II.

\begin{tabular}{lccc}
\hline \multirow{2}{*}{ Levedura (\%) } & GMD (g) & CMD (g) & CA (g/g) \\
\cline { 2 - 4 } & \multicolumn{3}{c}{ FASE I (22 A 45 dias) } \\
\hline 0 & 336 & 590 & 1,76 \\
5 & 354 & 594 & 1,68 \\
10 & 340 & 586 & 1,73 \\
15 & 340 & 543 & 1,74 \\
Análise de regressão & & \\
Efeito & ns & ns \\
$\mathrm{R}^{2}$ & 0,79 & 0,74 & $\mathrm{~ns}$ \\
CV(\%) & 5,88 & 3,82 & 0,76 \\
\multicolumn{3}{c}{} & FASE II (46 A 71 dias) \\
0 & 669 & 1.492 & 2,11 \\
5 & 742 & 1.506 & 2,03 \\
10 & 712 & 1531 & 2,15 \\
15 & 740 & 1.532 & 2,07 \\
& Análise de regressão & \\
Efeito & ns & ns & ns \\
$\mathrm{R}^{2}$ & 0,71 & 0,77 & 0,63 \\
CV(\%) & 5,99 & 4,21 & 6,14 \\
\hline
\end{tabular}

sem a adição de levedura. Com relação à fase II, também não ocorreram diferenças $(\mathrm{P}>0,05)$ para as características de desempenho, sendo que os animais que receberam a ração contendo $15 \%$ de levedura desidratada apresentaram, numericamente, melhor ganho de peso e, quando receberam $5 \%$, melhor conversão alimentar. No período experimental total (Tabela 3), de 22 a 71 dias de vida dos animais, os que foram alimentados com a ração contendo $5 \%$ de levedura desidratada apresentaram ganho de peso e conversão alimentar, respectivamente, 8,26\% e 7,20\% superiores aos animais alimentados com a dieta sem a inclusão de levedura. Portanto, os resultados não diferiram significativamente entre essas duas rações em questão. SPARK et al. (2005), trabalhando com o nível de substituição de 20\%, 40\% e 60\% pela quantidade de soja, observaram um melhor ganho de peso e melhoria na conversão alimentar de leitões desmamados com o nível de substituição de $40 \%$. Quanto à análise de regressão, não foi encontrada diferença para nenhum dos parâmetros estudados.

Os resultados obtidos para ganho de peso concordam com aqueles obtidos por BERTO (1985), que também não verificou efeito de níveis crescentes de levedura até 15\% de inclusão sobre o desempenho dos animais. No entanto, MIYADA et al. (1992), trabalhando com leveduras na alimentação de suínos, encontraram redução no ganho de peso e, segundo os autores, esta redução foi em virtude da diminuição da palatabilidade da ração, ocasionado pela utilização da levedura. LANDELL FILHO et al. (1994) verificaram uma diminuição no ganho de peso de leitões desmamados proporcionalmente ao aumento dos níveis de levedura na ração. TEGBE \& ZIMMERMAN (1977), trabalhando com leveduras para suínos, afirmaram que a levedura proporcionou uma consistência mais pegajosa às raçãos, diminuindo sua ingestão.

Quanto à conversão alimentar, o aumento dos níveis de levedura da ração produziu um efeito linear depressivo sobre ela (MIYADA \& LAVORENTI, 1979; MIYADA, 1987). Este resultado foi provavelmente decorrente de um maior consumo de ração pelos animais para balancear seu consumo energético, já que a levedura possui menor nível energético que o farelo de soja. De acordo com MOREIRA et al. (1998), a inclusão de níveis crescentes de levedura em rações para leitões piorou o ganho de peso e a conversão alimentar, sem, contudo, influenciar o consumo de ração e o custo em ração do quilo de peso ganho pelos leitões.

Não foram encontradas diferenças significativas para a morfologia intestinal entre os diferentes níveis de levedura desidratada estudados (Tabela 4). Estes resultados concordam com aqueles encontrados por CASTILLO et al. (2004), mas diferem

Tabela 3 - Ganho de peso diário (GMD), consumo médio diário (CMD) e conversão alimentar (CA) de leitões alimentados com rações contendo diferentes níveis de levedura desidratada (22 a 71 dias de idade).

\begin{tabular}{lccr}
\hline Levedura (\%) & Ganho de peso (kg) & Consumo de ração (kg) & Conversão alimentar (kg/kg) \\
\hline 0 & 499 & 1.038 & 2,08 \\
5 & 540 & 1.042 & 1,93 \\
10 & 523 & 1.062 & 2,03 \\
15 & 537 & 1.058 & 1,97 \\
Efeito & Análise de regressão & ns \\
$\mathrm{R}^{2}$ & $\mathrm{~ns}$ & $\mathrm{~ns}$ & 0,71 \\
$\mathrm{CV}(\%)$ & 0,62 & 0,75 & 4,23 \\
\hline
\end{tabular}

Ciência Rural, v.36, n.5, set-out, 2006. 
Tabela 4 - Altura das vilosidades, profundidade das criptas e relação vilosidade:cripta do duodeno e do jejuno de leitões em função dos diferentes níveis de levedura desidratada adicionados às rações

\begin{tabular}{lccc}
\hline Levedura (\%) & Altura dos vilos $(\mu \mathrm{m})$ & Profundidade das criptas $(\mu \mathrm{m})$ & Relação vilosidade:cripta \\
\hline & 354 & DUODENO & 3,75 \\
0 & 428 & 94 & 3,83 \\
5 & 346 & 112 & 3,89 \\
10 & 331 & 90 & 3,30 \\
15 & & 99 & $\mathrm{~ns}$ \\
Análise de regressão & $\mathrm{ns}$ & $\mathrm{ns}$ & 0,65 \\
Efeito & 0,54 & 0,78 & 19,29 \\
$\mathrm{R}^{2}$ & 23,37 & 13,42 & 3,88 \\
CV(\%) & & JEJUNO & 3,48 \\
& 315 & 82 & 3,76 \\
0 & 338 & 97 & 3,43 \\
5 & 324 & 89 & $\mathrm{~ns}$ \\
10 & 285 & 85 & 0,68 \\
15 & & & 16,80 \\
Análise de regressão & $\mathrm{ns}$ & $\mathrm{ns}$ & \\
Efeito & 0,65 & 15,06 & \\
$\mathrm{R}^{2}$ & 12,44 & & \\
CV(\%) & &
\end{tabular}

daqueles encontrados por THOMAZ (1996), o qual verificou que leitões alimentados com farelo de soja e abatidos 15 dias após a desmama apresentaram menor altura nas vilosidades e menor relação vilosidade:cripta do duodeno e do jejuno.

No entanto, BERTOL et al. (2000), analisando diferentes fontes protéicas para leitões desmamados, não encontraram diferenças estatísticas para altura das criptas e para altura das vilosidades aos 14 dias após o desmame. Contudo, os autores observaram uma redução na profundidade das criptas dos leitões alimentados com proteína concentrada de soja. De acordo com HANCOCK et al. (1990), a profundidade da cripta é um indicativo do nível de hiperplasia das células epiteliais, o que está relacionado, entre outros fatores, com o grau de antigenicidade da ração. A redução na profundidade das criptas indica menor nível de agressão à morfologia da parede intestinal provocada pelas rações (LI et al., 1991).

Como o ganho de peso não foi afetado pelos tratamentos, a altura da vilosidade também não foi influenciada pelos tratamentos no período observado. Para LI et al. (1991) e HANCOCK (1990), há uma relação positiva entre a altura da vilosidade no intestino delgado e a taxa de crescimento em leitões.

\section{CONCLUSÕES}

Os resultados obtidos permitiram concluir que a levedura desidratada (Saccharomyces cerevisiae) pode ser adicionada em até $15 \%$ nas rações para suínos na fase inicial. A morfologia intestinal, a altura das vilosidades e aprofundidade das criptas não foi influenciada pelos níveis de levedura utilizados na ração.

\section{REFERÊNCIAS}

BATTISTI, J.A. et al. Composição química e valores energéticos de alguns alimentos para suínos com diferentes idades. Revista Brasileira de Zootecnia, v.14, p.141-150, 1985.

BERTO, D.A. Levedura seca de destilaria de álcool de cana-de-açúcar (Saccharomyces spp) na alimentação de leitões em recria. 1985. 133f. Dissertação (Mestrado em Zootecnia) - Escola Superior de Agricultura "Luiz de Queiróz", Universidade de São Paulo.

BERTOL, T.M. et al. Efeito de diferentes fontes protéicas sobre o desempenho, composição corporal e morfologia intestinal em leitões. Revista Brasileira de Zootecnia, v.29, p.1735-1742, 2000.

CASTILLO, W. et al. Efeito da sustituição do farelho de soja pela levedura (Saccharomyces cerevisiae) como fonte protéica em dietas para leitões desmamados sobre a morfologia intestinal e atividade das enzimas digestivas intestinais. Archivos Latinoamericanos de Produccion Animal, v.12, p.21-27, 2004.

CERA, K.R. et al. Effect of age, weaning and postweaning diet on small intestinal growth and jejunal morphology in young swine. Journal of Animal Science, v.66, p.574-584, 1988.

FARIA, H.G. et al. Valor nutritivo das leveduras de recuperação (Sacharomyces sp) seca por rolo rotativo ou por spray-dry para coelhos em crescimento. Revista Brasileira de Zootecnia, v.29, p.1750-1753, 2000. 
FIALHO, E.T. et al. Composição química e valores energéticos de alguns alimentos para suínos. Pesquisa Agropecuária Brasileira, v.20, p.1419-1431, 1985

FRIENSEN, K.G. et al. The effect of pre and postweaning exposure to soybean meal on growth performance and on the immune response in the early-weaned pig. Journal of Animal Science, v.71, p.2089-2098, 1993

HANCOCK, J.D. et al. Effects of ethanol extraction and heat treatment of soybean flakes on function and morphology of pig intestine. Journal of Animal Science, v.68, p.32443251, 1990

LANDELL FILHO, L.C. et al. Utilização da levedura de centrifugação da vinhaça (Saccharomyces cerevisiae) como fonte protéica para leitões na fase inicial (10 a $30 \mathrm{~kg}$ de peso vivo). Revista Brasileira de Zootecnia, v.23, p.283-291, 1994

LI, D.F. et al. Interrelationship between hypersensitivy to soybean proteins and growth performance in early - weaned pigs. Journal of Animal Science, v.69, p.4062-4069, 1991.

LOPES, E.L. et al. Fontes de Lactose, Níveis de Lisina Dietéticos e Peso dos Leitões ao Desmame. Revista Brasileira de Zootecnia, v.6S, p.2340-2347, 2005.

MIYADA, V.S. A levedura seca na alimentação de suínos: Estudos adicionais sobre o seu valor protéico e vitamínico. 1987. 139f. Tese (Doutorado em Zootecnia) - Escola Superior de Agricultura “Luiz de Queiroz”, Universidade de São Paulo.

MIYADA, V.S.; LAVORENTI, A. Uso de levedura seca (Saccharomyces cerevisiae) de destilaria de álcool de cana-deaçúcar na alimentação de suínos em crescimento e acabamento. Revista Brasileira de Zootecnia, v.8, p.497-515, 1979.
MIYADA, V.S. et al. A levedura seca como ingrediente de rações fareladas ou peletizadas de leitões em recria. Revista Brasileira de Zootecnia, v.21, p.439-446, 1992.

MOREIRA, I. et al. Viabilidade da utilização da levedura de recuperação (Saccharomyces spp.), seca pelo método spraydry, na alimentação de leitões em fase de creche. Revista Brasileira de Zootecnia, v.27, p.319-324, 1998.

MOREIRA, I. et al. Uso da levedura seca por "spray-dry" como fonte de proteína para suínos em crescimento e terminação. Revista Brasileira de Zootecnia, v.31, p.962969, 2002.

SAS. Statistical Analysis System Institute. Ed.6.12. Cary, 2001. CD-ROOM.

SPARK, M. et al. Yeast (different sources and levels) as protein source in diets of reared piglets: effects on protein digestibility and N-metabolism. Journal of Animal Physiology and Animal Nutrition, v.89, p.184-188, 2005.

TEGBE, S.B.; ZIMMERMAN, D.R. Evolution of yeast single all protein in pig diets. Journal of Animal Science, v.45, p.1309-1315, 1977

THOMAZ, M.C. Digestibilidade da soja semi-integral extrusada e seus efeitos sobre o desempenho e morfologia intestinal de leitões na fase inicial. 1996. 66f. Tese (Doutorado em Zootecnia) - Faculdade de Medicina Veterinária e Zootecnia, Universidade Estadual Paulista.

ZANUTTO, C.A. Utilização de levedura de recuperação (Saccharomyces spp.) seca por spray-dry ou por rolo rotativo na alimentação de leitões na fase inicial. 1997. 54f. Dissertação (Mestrado em Zootecnia) - Universidade Estadual de Maringá. 